\title{
Models, algorithms and applications for location problems
}

\author{
Giuseppe Bruno $^{1}$ - Raffaele Cerulli ${ }^{2}$. \\ Monica Gentili ${ }^{2}$
}

Received: 28 March 2016 / Accepted: 31 March 2016 / Published online: 20 April 2016

(C) Springer-Verlag Berlin Heidelberg 2016

Locational analysis focuses on the development of models and methods to identify the best locations for a set of facilities within a given region in order to optimize a specific objective function. In this context, a wide variety of applications can be defined in both private industry and the public sector. Over the last several decades academics and practitioners have been proposing approaches that can represent the basis for support systems which can help decision makers in estimating the impact of decisions, combining various factors that affect the problems such as demand, location space, efficiencies, accessibility, and service level.

In an attempt to provide useful and updated insights, the triennial conference ISOLDE (International Symposium On Locational DEcision) represents the main event which gathers researchers and practitioners from all over the world with the goal of integrating different approaches from the fields of operations research, mathematics, management science, geography, economics and engineering.

This special issue of Optimization Letters is mainly dedicated (but not exclusively) to the 13th Edition of the ISOLDE Conference, hosted by the University of Naples Federico II, which took place 16-20 June 2014, in Naples and Capri (Italy). Participants from twenty different countries discussed about one hundred papers covering many of the most popular and innovative theoretical topics and applications.

For this special issue, we received 24 manuscripts, which were carefully reviewed through a rigorous refereeing process. Of the manuscripts submitted, 12 were accepted for inclusion in this special issue. A brief overview of each paper is given below; they are listed in alphabetical order by first author.

$\bowtie \quad$ Giuseppe Bruno

giuseppe.bruno@unina.it

1 Dipartimento di Ingegneria Industriale, Università degli Studi di Napoli Federico II, Napoli, Italy

2 Universita degli Studi di Salerno, Fisciano, Italy 
Ambrosino and Sciomachen [1] address a capacitated freight hub network with two transportation modes, namely road and rail. The authors present a mixed integer linear programming model and test it with some variations on randomly generated instances.

Barbati and Piccolo [2] study properties of equality measures to describe characteristics which may be useful for driving optimization procedures in the search for optimal (or near-optimal) solutions. The authors present a computational comparison based on two families of properties in the presence of a uniform distribution of demand points in a regular circular location space.

Bastian et al. [3] propose a multiple criteria decision analysis framework to optimize the military humanitarian assistance/disaster relief aerial delivery supply chain network. The model uses stochastic, mixed-integer, and weighted goal programming to optimize network design, logistics costs, staging locations, order quantities, and inventory levels.

Bianchi et al. [4] address the problem of "functional regionalization" and, in particular, the special case related to the identification of local labour market areas. They propose an approach based on the solution of minimum cut problems over an undirected graph built from information on commuting between different territorial units. They show the effectiveness of the proposed approach on real-world instances.

Bruno et al. [5] present a mathematical model to support location decisions for rationalizing facilities in non-competitive contexts. Computational results are shown to test the model, and an application to the Higher Education system in an Italian region is discussed.

Caramia and Mari [6] study a capacitated facility location problem with two decision makers. The authors develop a decomposition approach to cope with the bilevel structure of the problem and the integrality of a subset of variables under the control of the leader. The method is tested on a set of benchmark instances from the literature.

Di Puglia Pugliese et al. [7] address the mobile targets covering problem when unmanned aerial vehicles (UAVs) are used. Mixed integer non-linear optimization models are proposed together with heuristic procedures. A comparison of the efficiency and effectiveness of the models and heuristics is carried out.

Khodaparasti et al. [8] present an integrated location-allocation model balancing efficiency and equity criteria combining facility location analysis and data envelopment analysis. To illustrate the viability of the proposed approach, the authors investigate the potential application of the model to the design of an emergency medical service system.

The paper by Ogryczak and Olender [9] addresses the Weighted Ordered Median Problem which includes as a particular case the Ordered Median Problem. The main difference of this model with respect to the Ordered Median Problem is the incorporation of the demand weights by appropriately rescaling clients' measures within the distribution of distances. The authors present linear programming formulations for the optimization of the Weighted Ordered Median Problem with monotonic preferential weights and an MILP model for the general case. Computational experiments of the models presented in the paper are also described.

Saif and Elhedhli [10] propose a Lagrangian relaxation approach to solve a multiproduct uncapacitated facility location problem with concave costs. 
Sterle et al. [11] address the sensor placement problem (SPP) which consists of determining the number and location of sensors to cover all of the region of interest or a significant part of it. They focus on the placement of either omnidirectional or directional sensors to cover two-dimensional and three-dimensional areas. The authors present two ILP formulations and discuss their computational performance on a realworld scenario.

Triki [12] investigates the use of combinatorial auctions for the procurement of transportation services. The analysis focuses on the point of view of the carrier, who is interested in submitting to the auction a selected bundle of loads that reduces the movement of empty vehicles in his transportation network. The proposed solution method is based on the use of a location approach, usually used in the context of facility planning.

We wish to thank the Editors in Chief for the kind opportunity, the authors for submitting such high-quality articles and the referees for their excellent reviews. We would also like to thank all the people who helped organize the conference and contributed to its success.

\section{Giuseppe Bruno, Raffaele Cerulli and Monica Gentili}

\section{References}

1. Ambrosino, D., Sciomachen, A.: A capacitated hub location problem in freight logistics multimodal networks. Optim. Lett. 1-27 (2016). doi:10.1007/s11590-016-1022-8

2. Barbati, M., Piccolo, C.: Equality measures properties for location problems. Optim. Lett. 1-18 (2015). doi:10.1007/s11590-015-0968-2

3. Bastian, N.D., Griffin, P.M., Spero, E., Fulton, L.V.: Multi-criteria logistics modeling for military humanitarian assistance and disaster relief aerial delivery operations. Optim. Lett. 1-33 (2015). doi:10. 1007/s11590-015-0888-1

4. Bianchi, G., Bruni, R., Reale, A., Sforzi, F.: A min-cut approach to functional regionalization, with a case study of the Italian local labour market areas. Optim. Lett. 1-19 (2015). doi:10.1007/ s11590-015-0980-6

5. Bruno, G., Genovese, A., Piccolo, C.: Capacity management in public service facility networks: a model, computational tests and a case study. Optim. Lett. 1-21 (2015). doi:10.1007/ s11590-015-0923-2

6. Caramia, M., Mari, R.: A decomposition approach to solve a bilevel capacitated facility location problem with equity constraints. Optim. Lett. 1-23 (2015). doi:10.1007/s11590-015-0918-Z

7. Di Puglia Pugliese, L., Guerriero, F., Zorbas, D., Razafindralambo, T.: Modelling the mobile target covering problem using flying drones. Optim. Lett. 1-32 (2015). doi:10.1007/s11590-015-0932-1

8. Khodaparasti, S., Maleki, H.R., Bruni, M.E., Jahedi, S., Beraldi, P., Conforti, D.: Balancing efficiency and equity in location-allocation models with an application to strategic EMS design. Optim. Lett. 1-18 (2015). doi:10.1007/s11590-015-0929-9

9. Ogryczak, W., Olender, P.: Ordered median problem with demand distribution weights. Optim. Lett. 1-16 (2015). doi:10.1007/s11590-015-0990-4

10. Saif, A., Elhedhli, S.: A Lagrangian heuristic for concave cost facility location problems: the plant location and technology acquisition problem. Optim. Lett. 1-14 (2016). doi:10.1007/s11590-016-0998-4

11. Sterle, C., Sforza, A., Amideo, A.E., Piccolo, C.: A unified solving approach for two and three dimensional coverage problems in sensor networks. Optim. Lett. 1-23 (2016). doi:10.1007/ s11590-016-1014-8

12. Triki, C.: Location-based techniques for the synergy approximation in combinatorial transportation auctions. Optim. Lett. 1-15 (2015). doi:10.1007/s11590-015-0909-0 